\title{
Análise de livros didáticos sobre o tema "morcegos"
}

\author{
Analysis in the textbooks on "bats"
}

Maiara Jaloretto Barreiro ${ }^{1}$. Henrique Ortêncio Filho ${ }^{2}$

Resumo: Morcegos provocam medo, são considerados pouco carismáticos para a população em geral e são raras as divulgações de seus benefícios ecológicos. Os livros didáticos podem acrescentar ou reforçar alguns equívocos, estereótipos e mitificações, além de falhas conceituais, informações incorretas ou de cunho discriminatório. Esta pesquisa teve como objetivo analisar o conteúdo sobre quirópteros dos livros didáticos, disponíveis na biblioteca municipal e em escolas públicas de Assis, São Paulo, além de avaliar como são veiculadas as informações pelas editoras com influência educacional. Dos 33 livros avaliados, apenas 26 continham informações sobre morcegos. Havia poucos erros conceituais ou informações distorcidas, mas, a qualidade informativa foi considerada insatisfatória e os discursos, superficiais. Constatou-se a necessidade de enfatizar as informações sobre os diversos papéis ecológicos dos morcegos e da inclusão de informações médico-sanitárias e profiláticas como forma de contribuição à saúde pública brasileira.

Palavras-chave: Ensino de ciências. Quirópteros. Ensino de biologia. Livro didático. Morcegos.

\begin{abstract}
Bats cause fear; they are not considered charismatic by the general population and the disclosure of their ecological benefits are rare. Textbooks can add or strengthen some misconceptions, stereotypes, and myths, as well as conceptual flaws, incorrect information or negative discrimination. This study aimed to analyse the content on chiropters in textbooks available at the municipal library and public schools of Assis, São Paulo, Brazil, and to evaluate how information is transmitted by publishers with educational influence. In 33 reviews of books, only 26 contained information about bats. There were a few misconceptions or misinformation, but the informative quality was considered unsatisfactory and the text superficial. It found there was a need to emphasize information about the several ecological roles of bats and to include medical and prophylactic health information as a contribution to the Brazilian public health.
\end{abstract}

Keywords: Science teaching. Chiropters. Biology teaching. Textbook. Bats.

\footnotetext{
${ }^{1}$ Universidade Estadual de Maringá (UEM), Maringá, PR, Brasil. E-mail: <maiara_jaloretto@hotmail.com>

${ }^{2}$ UEM, Departamento de Ciências, Maringá, PR, Brasil.
} 


\section{Introdução}

Os morcegos pertencem à Ordem Chiroptera - mamíferos mais diversos do mundo - e possuem a segunda maior riqueza entre espécies brasileiras, sendo superados apenas pela Ordem Rodentia (REIS et al., 2007). No Brasil, foram registradas 174 espécies distribuídas em 65 gêneros e nove famílias, as quais estão presentes em todos os biomas, desde a Floresta Amazônica até os pampas gaúchos (PAGLIA et al., 2012).

Segundo Brasil (1998), as modificações antrópicas na natureza favorecem o desenvolvimento de vários grupos de animais. Ambientes urbanos mal planejados permitem o surgimento de morcegos fitófagos e insetívoros (PACHECO et al., 2010), utilizando construções como abrigos, ou alimentando-se dos insetos atraídos pela iluminação pública, dos frutos e flores providos pelas árvores nas vias públicas e nos quintais das casas (BRASIL, 1998).

Dessa forma, várias espécies de morcegos beneficiam-se com a falta de planejamento urbano e ali permanecem, mas, sua aproximação com a população tem gerado alguns transtornos que reforçam a visão negativa de algumas pessoas em relação a esses pequenos voadores. De acordo com Pacheco et al. (2010), morcegos são considerados pragas domésticas em áreas urbanas, sendo reclamações comuns dos moradores: a entrada dos animais em edificações, o mau cheiro provocado pelas suas fezes e urina, as vocalizações, entre outros.

Paiva (2010) explica que os morcegos provocam medo e são considerados pouco carismáticos para a população em geral, principalmente para crianças. Ademais, alguns fatores, como o hábito noturno e o fato de repousarem de cabeça para baixo contribuem para esse temor. Somam-se, ainda, todos os folclores, lendas e superstições envolvendo os morcegos. Uieda (2007) acredita que os hematófagos são os grandes responsáveis por essa aversão, visto que a população leiga crê que todos os quirópteros se alimentam de sangue, embora apenas três espécies neotropicais possuam esse hábito alimentar.

Scavroni, Paleari e Uieda (2008) não apenas consideram raras as informações divulgadas sobre as funções ecológicas desses animais, como também, observam a necessidade de realização de atividades que forneçam conhecimentos sobre as diversas relações ambientais envolvendo os morcegos e sobre os perigos médico-sanitários relacionados.

Em concordância, Oliveira e Silva (2009) ressaltam que as crianças recebem influência cultural na forma de conhecimentos fantasiosos ou errados a respeito dos morcegos, e isso se reflete na perpetuação da informação distorcida pela sociedade.

$\mathrm{Na}$ maioria das escolas, o processo de ensino é auxiliado por livros didáticos e o seu conteúdo é tão relevante que, de acordo com Molina (1987), os professores utilizam esse recurso como base teórica das aulas, estando presentes em sala com a mesma frequência que os próprios docentes, disseminando informações em todas as camadas da sociedade escolar (SANDRIN; PUORTO; NARDI, 2005). O Ministério da Educação apoia que os livros didáticos escolhidos em seu Programa Nacional do Livro Didático (PNLD) (BRASIL, 2013) devem servir de subsídio para a educação básica, mas, tal componente tem sido superestimado por muitos educadores, tornando-se necessária a diminuição da sua importância como recurso didático (MACHADO, 1996). Sobre o conteúdo das obras educacionais, Machado (1996, p. 37) considera ainda, que “[...] se há uma desatualização de que os livros didáticos efetivamente padecem, ela se refere muito mais à concepção de conhecimento que implicitamente veiculam, em todas as áreas, do que a informações tópicas nos diversos temas abordados". 
De acordo com Megid Neto e Fracalanza (2003), os livros didáticos são capazes de acrescentar ou reforçar alguns equívocos, estereótipos e mitificações com relação ao conhecimento científico, ambiental e outros, relacionados ao ensino de Ciências Naturais. É importante que as informações contidas nos livros didáticos sejam corretas e suficientes, pois são os recursos de ensino mais utilizados, e a melhora na qualidade dos mesmos contribui para o progresso da aprendizagem. (FERREIRA; SOARES, 2008).

O currículo do Estado de São Paulo discute que a educação deve formar cidadãos para a vida, de modo que sejam capazes de refletir sobre as transformações antrópicas, de participar e atuar no mundo globalizado, no qual os avanços científicos e tecnológicos trazem benefícios ao homem, mas, podem, também, causar mudanças negativas na natureza (SÃO PAULO, 2011).

Esse tipo de pesquisa é relevante, uma vez que muitos livros didáticos ainda apresentam falhas conceituais, informações incorretas ou difundem informações de cunho discriminatório/ preconceituoso (SUCCI; WICKBOLD; SUCCI, 2005). Assim, esta pesquisa teve como objetivo analisar o conteúdo das informações contidas nos livros didáticos disponíveis para os alunos e professores da rede educacional do estado de São Paulo com relação à Ordem Chiroptera.

\section{Metodologia}

Para a realização deste trabalho foram utilizados livros de ciências naturais $\left(6^{\circ}\right.$ ao $9^{\circ}$ anos do ensino fundamental) e de biologia (séries do ensino médio), obras estas pertencentes à Biblioteca Pública da cidade de Assis, SP, e outras distribuídas pela Secretaria de Educação do Estado de São Paulo para uso dos docentes e discentes de suas escolas públicas. As obras consultadas foram utilizadas no ano de 2014 e empregadas no quadriênio anterior (já recolhidas em depósito). Na Biblioteca Pública Municipal, selecionaram-se os livros mais atuais disponíveis, englobando obras do ano 2000 até 2014, visto que os volumes de ciências e biologia do acervo da Instituição possuem publicações de anos diversos, a partir de 1980.

A escolha dos livros didáticos baseou-se na facilidade e disponibilidade de acesso que os professores da rede pública estadual teriam em encontrar materiais de pesquisa para a preparação de suas aulas, seguidas da procura dos alunos de leituras complementares para aumentar os conhecimentos adquiridos na escola.

Devido à constante aproximação dos morcegos com a sociedade, foram previamente selecionados 32 manuais didáticos, a fim de descobrir quais são os conhecimentos apresentados à comunidade estudantil e avaliar como esses são veiculados pelas editoras com influência educacional.

Esta pesquisa é qualitativa do tipo de análise documental. Para a execução dessas análises, quaisquer formas de citações, textos descritivos, exercícios, imagens e ilustrações referentes a morcegos, presentes no decorrer das obras, foram considerados. As metodologias propostas por Assis, Pimenta e Schall (2013) e Cardoso-Silva e Oliveira (2013) foram adaptadas para este estudo, a saber: (1) estrutura; (2) conteúdo, cientificidade dos conceitos e presença de aspectos éticos ou estigmatizados; (3) linguagem e compreensibilidade dos leitores; (4) ilustrações. A lista completa dos materiais examinados encontra-se no Quadro 1. 
Quadro 1. Livros didáticos usados na pesquisa

\begin{tabular}{|c|c|}
\hline \multirow[t]{2}{*}{ Código } & Referência \\
\hline & Obras do Ensino fundamental ( $6^{\circ}$ ao $9^{\circ}$ anos) \\
\hline EF01 & $\begin{array}{l}\text { BARROS, C.; PAULINO, W. R. Ciências: manual do professor: } 6^{a} \text { série. São Paulo: Ática, } \\
2006 .\end{array}$ \\
\hline EF02 & $\begin{array}{l}\text { BORTOLOZZO, S.; MALUHY, S. Projeto educação para o século XXI: } 6^{a} \text { série. São } \\
\text { Paulo: Moderna, 2002. }\end{array}$ \\
\hline EF03 & $\begin{array}{l}\text { CANTO, E. L. Ciências naturais: aprendendo com o cotidiano, } 6^{\circ} \text { ano. 3. ed. São Paulo: } \\
\text { Moderna, } 2009 .\end{array}$ \\
\hline EF04 & $\begin{array}{l}\text { CANTO, E. L. Ciências naturais: aprendendo com o cotidiano, } 7^{\circ} \text { ano. 3. ed. São Paulo: } \\
\text { Moderna, } 2009 \text {. }\end{array}$ \\
\hline EF05 & $\begin{array}{l}\text { CANTO, E. L. Ciências naturais: aprendendo com o cotidiano, } 8^{\circ} \text { ano. 3. ed. São Paulo: } \\
\text { Moderna, } 2009 .\end{array}$ \\
\hline EF06 & $\begin{array}{l}\text { CANTO, E. L. Ciências naturais: aprendendo com o cotidiano, } 9^{\circ} \text { ano. 3. ed. São Paulo: } \\
\text { Moderna, } 2009 .\end{array}$ \\
\hline EF07 & $\begin{array}{l}\text { CARVALHO, W.; GUIMARÃES, M. Ciências para nosso tempo: } 7^{\circ} \text { ano. Curitiba: } \\
\text { Positivo, 2011. }\end{array}$ \\
\hline EF08 & $\begin{array}{l}\text { CARVALHO, W.; GUIMARÃES, M. Ciências para nosso tempo: } 8^{\circ} \text { ano. Curitiba: } \\
\text { Positivo, 2011. }\end{array}$ \\
\hline EF09 & $\begin{array}{l}\text { CARVALHO, W.; GUIMARÃES, M. Ciências para nosso tempo: } 9^{\circ} \text { ano. Curitiba: } \\
\text { Positivo, 2011. }\end{array}$ \\
\hline EF10 & $\begin{array}{l}\text { FIGUEIREDO, M. T.; CONDEIXA, M. C. G. Ciências: atitude e conhecimento, } 6^{\circ} \text { ano. } \\
\text { São Paulo: FTD, } 2009 \text {. }\end{array}$ \\
\hline EF11 & $\begin{array}{l}\text { FIGUEIREDO, M. T.; CONDEIXA, M. C. G. Ciências: atitude e conhecimento, } 7^{\circ} \text { ano. } \\
\text { São Paulo: FTD, } 2009 \text {. }\end{array}$ \\
\hline EF12 & $\begin{array}{l}\text { FIGUEIREDO, M. T.; CONDEIXA, M. C. G. Ciências: atitude e conhecimento, } 8^{\circ} \text { ano. } \\
\text { São Paulo: FTD, } 2009 .\end{array}$ \\
\hline EF13 & $\begin{array}{l}\text { FIGUEIREDO, M. T.; CONDEIXA, M. C. G. Ciências: atitude e conhecimento, } 9^{\circ} \text { ano. } \\
\text { São Paulo: FTD, } 2009 .\end{array}$ \\
\hline
\end{tabular}

continua

\section{Resultados e discussão}

Uma leitura seletiva foi feita em cada livro didático em busca de informações sobre morcegos. As obras EF03, EF06, EF08, EM03, EM05 e EM11 não apresentaram o conteúdo, sendo que EM05 tratava inteiramente da matéria biologia celular sem a abordagem de assuntos em que morcegos normalmente são considerados, podendo justificar a ausência da temática buscada neste estudo. 
Quadro 1. continuação

\begin{tabular}{|c|c|}
\hline \multirow[t]{2}{*}{ Código } & Referência \\
\hline & Obras do Ensino Médio ( $1^{\circ}$ ao $3^{\circ}$ anos $)$ \\
\hline EM01 & $\begin{array}{l}\text { ADOLFO, A.; CROZETTA, M.; LAGO, S. Biologia: ensino médio. 2. ed. São Paulo: } \\
\text { IBEP, } 2005 .\end{array}$ \\
\hline EM02 & $\begin{array}{l}\text { AMABIS, J. M.; MARTHO, G. R. Fundamentos da biologia moderna. 3. ed. São Paulo: } \\
\text { Moderna, 2002. }\end{array}$ \\
\hline EM03 & $\begin{array}{l}\text { AMABIS, J. M.; MARTHO, G. R. Biologia: biologia das células. 2. ed. São Paulo: Moderna, } \\
2004 .\end{array}$ \\
\hline EM04 & $\begin{array}{l}\text { BRITO, A. E.; FAVARETTO, J. A. Biologia: uma abordagem evolutiva e ecológica. São } \\
\text { Paulo: Moderna, } 1997 .\end{array}$ \\
\hline EM05 & $\begin{array}{l}\text { CESAR, S. J.; SEZAR, S. Biologia: as características da vida, biologia celular, vírus - entre } \\
\text { moléculas e células, a origem da vida e histologia animal. 8. ed. São Paulo: Saraiva, } 2005 .\end{array}$ \\
\hline EM06 & $\begin{array}{l}\text { CESAR, S. J.; SEZAR, S. Biologia: seres vivos - estrutura e função. 8. ed. São Paulo: } \\
\text { Saraiva, } 2005 .\end{array}$ \\
\hline EM07 & $\begin{array}{l}\text { CESAR, S. J.; SEZAR, S. Biologia: genética, evolução e ecologia. 7. ed. São Paulo: Saraiva, } \\
2005 .\end{array}$ \\
\hline EM08 & LAURENCE, J. Biologia: ensino médio, volume único. São Paulo: Nova Geração, 2005. \\
\hline EM09 & $\begin{array}{l}\text { LINHARES, S.; GEWANDSZNAJDER, F. Biologia hoje: genética, evolução e ecologia. } \\
\text { São Paulo: Ática, 1997. v. } 3 .\end{array}$ \\
\hline EM10 & $\begin{array}{l}\text { LINHARES, S.; GEWANDSZNAJDER, F. Biologia: volume único, livro do professor. } \\
\text { São Paulo: Âtica, } 2005 .\end{array}$ \\
\hline EM11 & $\begin{array}{l}\text { LINHARES, S.; GEWANDSZNAJDER, F. Biologia hoje: citologia, reprodução e } \\
\text { desenvolvimento, histologia e origem da vida. São Paulo: Ática, } 2010 .\end{array}$ \\
\hline EM12 & $\begin{array}{l}\text { LINHARES, S.; GEWANDSZNAJDER, F. Biologia hoje: genética, evolução e ecologia. } \\
\text { São Paulo: Ática, } 2010 .\end{array}$ \\
\hline EM13 & $\begin{array}{l}\text { LINHARES, S.; GEWANDSZNAJDER, F. Biologia hoje: os seres vivos. São Paulo: Ática, } \\
2010 .\end{array}$ \\
\hline EM14 & $\begin{array}{l}\text { LOPES, S. G. B. C. Bio: volume único - completo e atualizado. 11. ed. São Paulo: Saraiva, } \\
2001 .\end{array}$ \\
\hline EM15 & LOPES, S.; ROSSO, S. Bio: volume 1. São Paulo: Saraiva, 2010. \\
\hline EM16 & LOPES, S.; ROSSO, S. Bio: volume 2. São Paulo: Saraiva, 2010. \\
\hline EM17 & LOPES, S.; ROSSO, S. Bio: volume 3. São Paulo: Saraiva, 2010. \\
\hline EM18 & MACHADO, S. Biologia para o ensino médio: volume único. São Paulo: Scipione, 2003. \\
\hline EM19 & $\begin{array}{l}\text { PAULINO, W. R. Biologia, volume 2: seres vivos/fisiologia - livro do professor. São } \\
\text { Paulo: Ática, } 2005 .\end{array}$ \\
\hline
\end{tabular}

Fonte: Elaborado pelos autores. 


\section{Forma de abordagem do tema "morcegos" nos livros didáticos}

Os modos de apresentação dos conteúdos foram: 41\% na forma de imagens (ilustrações e fotografias), $38 \%$ na forma de texto e $21 \%$ em exercícios.

Com relação aos textos, a maioria dos autores utilizou discursos descritivos/explicativos, sem ênfase especial no decorrer das obras. Outros, porém, utilizaram quadros de leitura com títulos chamativos: "discuta estas idéias" (EF01, p. 242), "parecem do mal, mas são do bem” (EF02, p. 102), "em destaque: importância do ultrassom para alguns animais" (EF05, p. 196) e "de olho no mercado de trabalho: médico veterinário" (EM18, p. 282). Essas estratégias de destaque da informação atraem a atenção do aluno para a leitura e proporcionam maior potencial de aprendizado.

Os exercícios trabalhavam a interpretação de textos e o entendimento dos temas abordados nos capítulos dos livros. Poucos ofereciam subsídios para o desenvolvimento de questionamentos profundos, que exigiam um pouco mais de raciocínio, assim como os empregados por EM15 e EM17. Tais autores expuseram um estudo de caso com enfoque à influência antrópica e ambiental na população de morcegos de uma determinada região (EM15) e utilizaram linguagem científica, seguida da abordagem dos graus de ameaça de extinção de espécies, conforme classificações do Ministério do Meio Ambiente (EM17). Essas atividades, quando trabalhadas em sala de aula, demonstram um aspecto prático da profissão no ramo biológico e são eficientes em despertar o interesse dos alunos para a ciência.

O trabalho de percepção acerca de morcegos, de Silva et al. (2009), apontou que muitos adolescentes do ensino médio do município de Japurá, no estado do Paraná, pensavam que morcegos fossem ratos velhos e outros, sequer, sabiam que esses animais se enquadravam no grupo dos mamíferos, imaginando que fossem aves. Tal confusão pode ser resultado da carência da relação entre sociedade leiga e morcegos. Sugere-se que as imagens do animal em livros didáticos possam estabelecer este contato, proporcionando o entendimento e identificação desses grupos anteriormente apontados, auxiliando na eliminação de conceitos estigmatizados.

Nos livros didáticos, as imagens estão inseridas em temas diversos e é comum encontrar representação dos morcegos como exemplos de mamíferos, diagramas evolutivos ou de anatomia comparada, esquemas do funcionamento da ecolocalização, fotografias de morcegos em repouso, voando e consumindo frutos ou néctar (Figura 1).

É evidente a importância do uso das imagens no auxílio didático para a percepção e construção de conceitos (RUPPENTHAL; SCHETINGER, 2013) e o destaque nos materiais didáticos proporcionados por fotos, em que os animais apresentam aspecto carismático, é notável (Figura 2). São os casos em que morcegos visitavam flores (EF07) ou se alimentavam de frutos (EF01, EF04). Nesse caso, sobressai, ainda, a fotografia utilizada por EM08, na qual um morcego aparece com sua língua à mostra, o que pode sinalizar carisma ao leitor.

Vale lembrar que as fotografias precisam ser escolhidas com especial cuidado e adaptação à realidade brasileira. Aquelas utilizadas por EF02, EM08, EF04 e EF09, representam os morcegos com espécies da subordem Yinpterochiroptera (Figura 3), sem apontar que sua ocorrência geográfica natural está restrita aos países do velho mundo (STAWSKI; WILLIS; GEISER, 2014), e que os mesmos não ocorrem no Brasil. 
Figura 1. Fotografias de morcegos em livros didáticos. Morcego durante o voo (a) e em repouso (b) e (c)

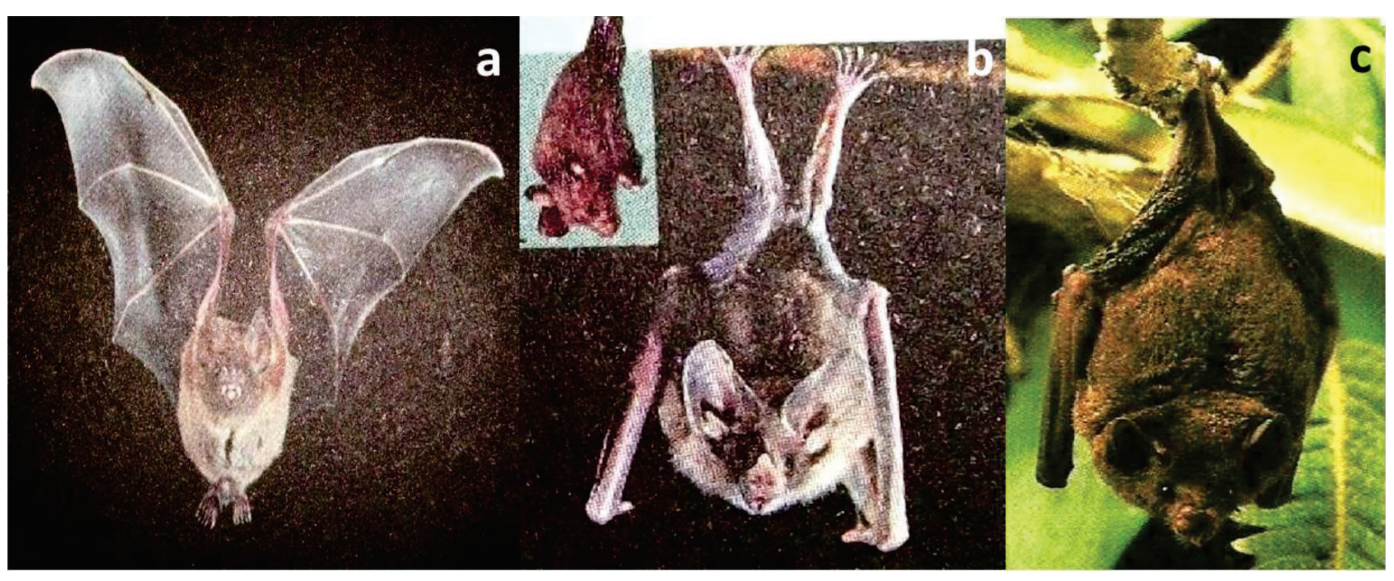

Fontes: (a) EM17; (b) EF11 e (c) EM09.

Figura 2. Representações em livros didáticos de morcegos considerados carismáticos

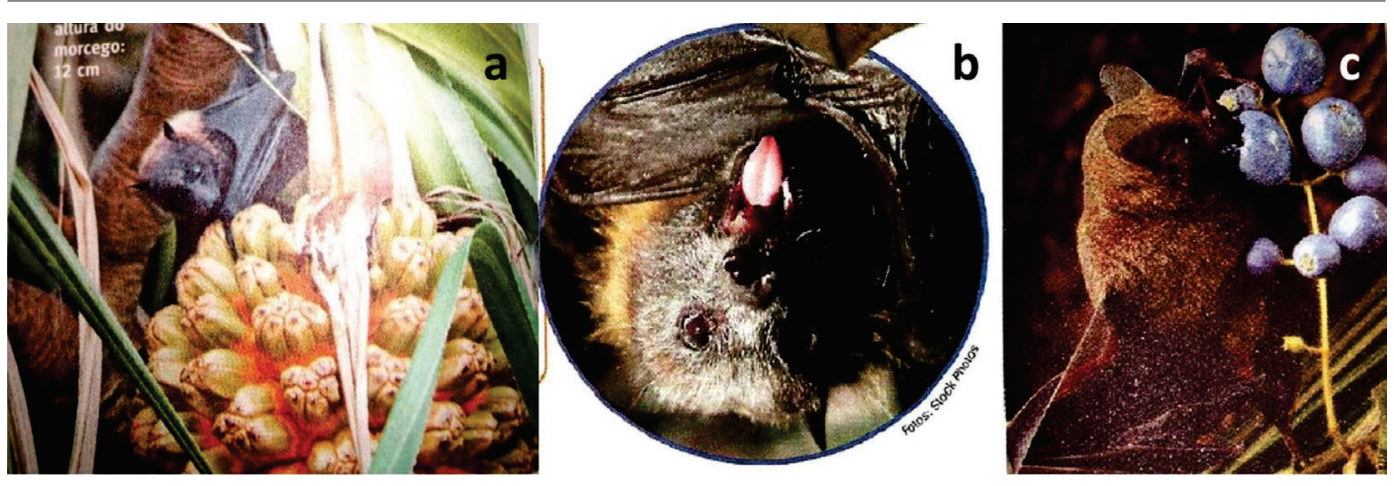

Fontes: (a) EF04; (b) EM08 e (c) EF01.

Os professores devem estar preparados para uma discussão interessante que pode surgir pelo emprego de fotos em EM19, EF13 e EF07, as quais mostram os dentes dos quirópteros (Figura 4), podendo provocar comparações relacionadas à figura caricata dos vampiros. 
Barreiro, M. J.; Ortêncio Fiho, H.

Figura 3. Representações em livros didáticos de morcegos pertencentes à subordem Yinpterochiroptera, os quais não ocorrem no Brasil

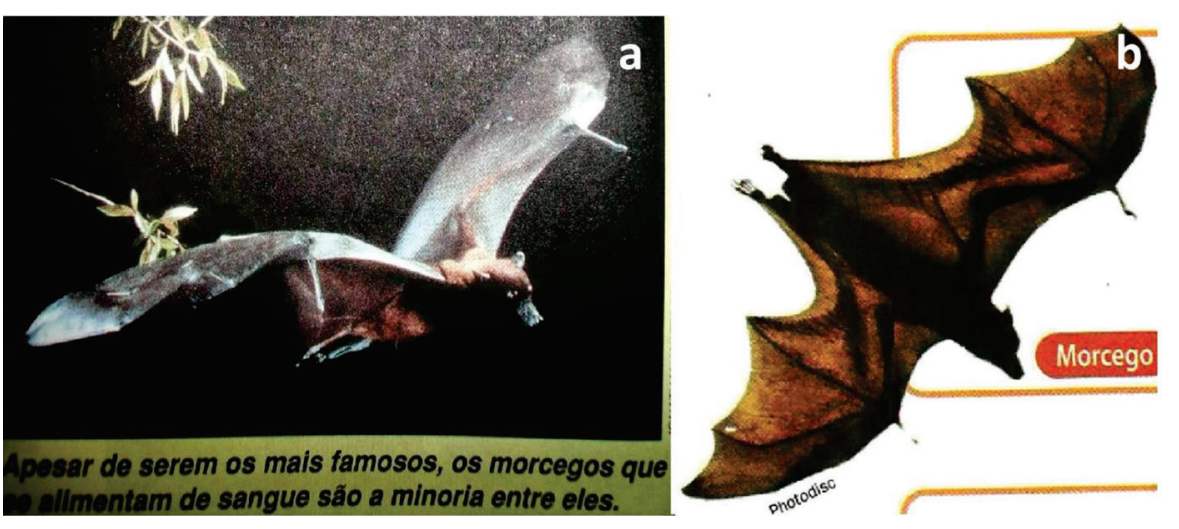

Fontes: (a) EF02 e (b) EM08.

Figura 4. Representações em livros didáticos de morcegos com dentes à mostra

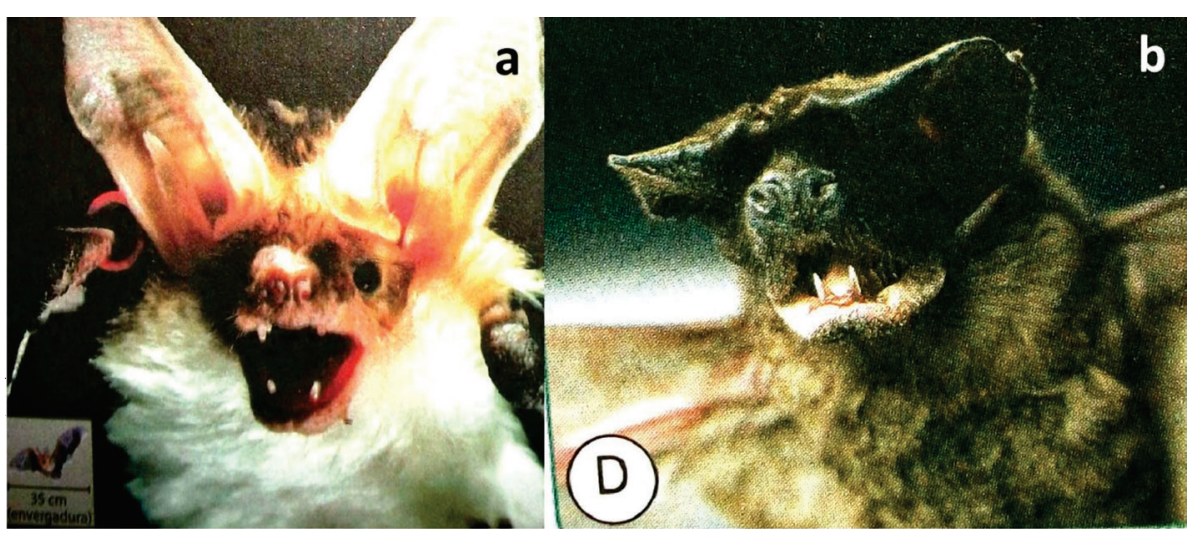

Fontes: (a) EF13 e (b) EM19.

\section{Assuntos abordados nos livros didáticos}

Buscou-se conhecer a frequência em que os morcegos são abordados e em quais tópicos estão inseridos nos livros didáticos (Quadro 2). A temática mais comum nas obras pesquisadas foi "mamíferos", seguida de "analogia/homologia" e "polinização".

A ocorrência dos morcegos foi mencionada nos livros didáticos somente para florestas tropicais (EF07) e para a Mata Atlântica (EM09; EF07), embora ocorram em todos os biomas terrestres brasileiros (PAGLIA et al., 2012). Essa informação deve ser incluída nos livros para salientar a variedade de distribuição geográfica do grupo. 
Quadro 2. Principais enfoques registrados em livros didáticos de ciências sobre o tema "Morcegos"

\begin{tabular}{|l|c|c|}
\hline \multicolumn{1}{|c|}{ Temática abordada } & Quantidade & Representatividade \\
\hline Hábito noturno/diurno & 01 & $1,4 \%$ \\
\hline Ambiente terrestre & 01 & $1,4 \%$ \\
\hline Biomas brasileiros & 03 & $4,1 \%$ \\
\hline Mamíferos & 12 & $16,7 \%$ \\
\hline Quirópteros & 08 & $11,1 \%$ \\
\hline Polinização & 10 & $13,9 \%$ \\
\hline Vertebrados & 02 & $2,8 \%$ \\
\hline Ecolocalização & 05 & $6,9 \%$ \\
\hline Dispersão de sementes & 01 & $1,4 \%$ \\
\hline Amônia & 01 & $1,4 \%$ \\
\hline Pirâmides ecológicas & 01 & $1,4 \%$ \\
\hline Ecologia de populações & 01 & $1,4 \%$ \\
\hline Homologia/analogia & 11 & $15,3 \%$ \\
\hline Classificação biológica & 02 & $2,8 \%$ \\
\hline Irradiação adaptativa & 07 & $9,7 \%$ \\
\hline Hidrofobia & 03 & $4,1 \%$ \\
\hline Evolução & 01 & $1,4 \%$ \\
\hline Cadeia alimentar & 02 & $2,8 \%$ \\
\hline Total & 72 & $100 \%$ \\
\hline & & \\
\hline
\end{tabular}

Fonte: elaborado pelos autores.

Ao abordar analogia/homologia, EM01, EM06, EM07, EM08, EM09, EM10, EM12, EM14 e EM16 utilizaram figuras da anatomia dos membros anteriores de diversos animais (Figura 5), enquanto EM02, EM07 e EM09 indicaram, também, um possível ancestral em comum entre os mamíferos. $\mathrm{O}$ uso das ilustrações comparativas nessa temática é importante para a visualização das diferenças e semelhanças entre os grupos de animais e auxilia no entendimento desses processos evolutivos. 
Figura 5. Ilustrações em livros didáticos representando homologia entre animais
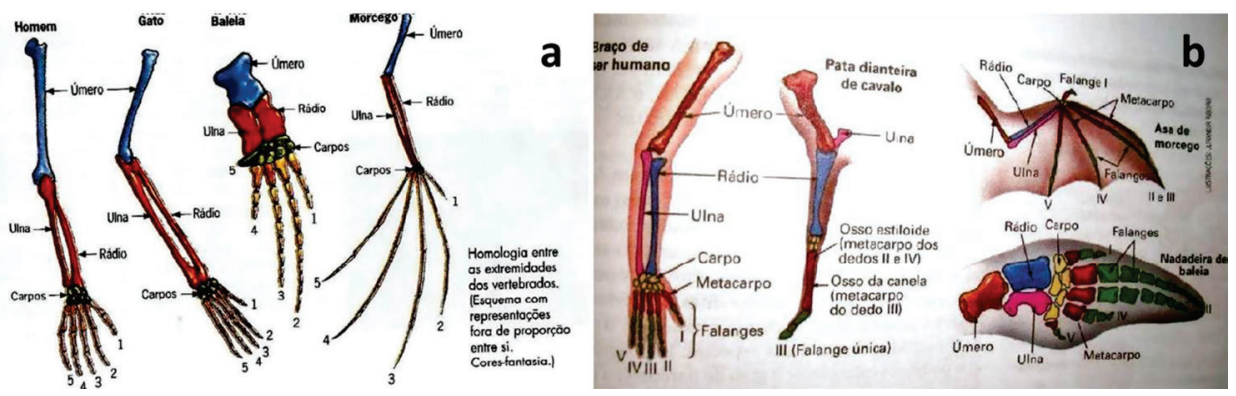

Fontes: (a) EM06 e (b) EM16.

Os autores, constantemente, mencionam quirópteros como animais representantes da classe Mammalia (EM06; EF01; EF04; EF07; EF11; EF12), sendo, em sua maioria, referida como exceção do grupo - como os únicos mamíferos capazes de voar (EM01; EM17; EM19), bem como suas adaptações para tal (EM14; EM19). Mohr (1994) salienta a importância da apresentação de informações e explicações desenvolvidas nos livros didáticos, de modo a proporcionar o entendimento do aluno pelo assunto abordado. Porém, com relação à biologia dos morcegos, os livros analisados abordaram o tema com pouco destaque e apresentaram conceitos gerais bastante superficiais e explicações simplistas.

\section{Polinização, dispersão e guano dos morcegos}

Os livros didáticos (EM04; EM13; EM19; EF07) abordam a questão ecológica da polinização realizada por morcegos e muitos explanam sobre as características adaptativas da flor para a quiropterofilia, atentando para a coloração branca e clara das pétalas, o odor atrativo aos quirópteros e a produção de néctar. EF02 explicam o porquê da polinização realizada pelos morcegos ainda ser pouco conhecida

[...] Talvez os morcegos não sejam tão conhecidos por esse papel de polinizadores porque são de hábitos noturnos: as flores brancas, mais visíveis à noite do que flores de outras cores, exalam seu perfume nesse período para que esses animais, atraídos pelo cheiro doce, procedam à polinização. (EF02, p. 102).

Tanto a polinização quanto a dispersão são tópicos de conhecimento imprescindível para professores e alunos, uma vez que as relações entre as plantas e seus agentes polinizadores e dispersores são fundamentais para a estruturação das comunidades ecológicas e podem influenciar na riqueza, distribuição e abundância de espécies (YAMAMOTO; KINOSHITA; MARTINS, 2007). São assuntos que poderiam ser abordados em conjunto, pois ambos auxiliam nos mecanismos de sucessão florestal e restauração da biodiversidade (VERÇOZA et al., 
2012). As informações apresentadas sobre o primeiro processo atentam corretamente para os processos evolutivo-adaptativos dos morcegos polinizadores e suas flores, as quais apresentam especificidades como a antese noturna, odor forte e desagradável (SILVA et al., 2009) e coloração pouco chamativa, geralmente branca ou esverdeada (COSTA; OLIVEIRA, 2013). O processo de dispersão com ênfase à questão ecológica dos morcegos foi explorado apenas por EF02 e EF04, embora a maioria dos livros didáticos informe também sobre a variedade alimentar dos morcegos, incluindo frutos. Os livros, no entanto, pouco esclarecem sobre o papel ecológico dos morcegos na dispersão de sementes, proporcionando um déficit na aprendizagem ecológica dos leitores.

EF09 (p. 104) discorre sobre a amônia liberada pela decomposição das fezes dos morcegos, relacionando as cavernas e os morcegos que nelas habitam com o cheiro da substância liberada em "podemos dizer que sentimos a presença de morcegos". A curiosidade foi disponibilizada na forma de quadro, atrativo à leitura, mas não apresenta qualquer tipo de explanação profilática ou informativa a respeito de algumas zoonoses que se desenvolvem no ambiente cavernícola habitado por morcegos, a exemplo da histoplasmose, doença provocada pelo agente fúngico Histoplasma capsulatum (TELES et al., 2014). Tampouco discorre sobre os excretas liberados pelos morcegos (guano) no interior das cavernas e sua importância para a fauna de invertebrados cavernícolas, ao disponibilizarem fontes alimentares através dos depósitos de guano (CAJAIBA, 2014), composto rico em nitrogênio que possibilita o desenvolvimento de fungos contribuintes na ciclagem de nutrientes (SALGADO, 2011).

\section{Raiva}

A obra didática EM06 (p. 184) generaliza a forma de contágio da virose pelos morcegos e confunde o leitor quando utiliza a palavra "transmitindo", ao invés da expressão "podendo transmitir", em: “[...] As espécies que se alimentam de sangue (hematófagas), chamadas de vampiros, atacam o gado e outros animais, inclusive o ser humano, transmitindo a raiva (hidrofobia), uma grave virose que, sem vacinação, é mortal".

EM18 e EM19 tratam o assunto de forma mais cautelosa e explicam que a transmissão da doença ao homem pode ocorrer por meio do contato com morcegos ou outros animais silvestres, embora em menores proporções, quando comparadas à transmissão por cães e gatos. A informação transmitida está correta, pois cães são os principais transmissores da enfermidade ao homem, seguidos dos morcegos, sejam eles hematófagos ou não (ALBAS et al., 2009).

A raiva é uma doença mortal que acomete o sistema nervoso de mamíferos. É transmitida quando o vírus existente na saliva do animal infectado entra em contato com a mucosa ou pele do animal susceptível (RAMOS, 2009). O tema deve ser trabalhado pelos professores com bastante cautela, já que a presença de preconceitos culturais em livros didáticos é muito frequente (AMARAL; MEGID-NETO, 1997). Considerando essa abordagem, a enfermidade é, muitas vezes, alvo de folclore, crenças religiosas, e pode originar mitos ou lendas relacionadas aos quirópteros (BATISTA; FRANCO; ROEHE, 2007). No contexto epidemiológico, o aluno deve, para segurança própria e de terceiros, conhecer os sintomas da doença e saber identificá-la e, também, prevenir-se. Entretanto, em nenhum dos livros pesquisados, foram discutidas medidas profiláticas, como, por exemplo, a importância de evitar o contato direto (manuseio) com animais silvestres, ou mesmo com animais domésticos desconhecidos - como cães de rua, além da necessidade de procurar um serviço médico adequado caso esse contato ocorra. 


\section{Ecolocalização}

A ecolocalização é utilizada pelos morcegos para determinar a distância ou posição de obstáculos e animais. Esse mecanismo é baseado na emissão de ondas ultrassônicas, seguida da reflexão da onda quando chega ao alvo, retornando na forma de eco (COELHO et al., 2012). Por tratar-se de um assunto bastante curioso, a obra didática de EF02 (p. 17) usa estratégias chamativas ao questionar "O que existe em comum entre um morcego e um avião? Além do fato de voarem, o som”. EF05 expôs o experimento do biólogo Lazzaro Spallanzani, em que os morcegos foram impedidos de ver ou escutar para que a capacidade dos seus sonares fosse avaliada.

A explanação dos livros didáticos sobre essa capacidade é bastante exemplificada por meio de figuras (Figura 6), facilitando o entendimento do processo de emissão/recebimento dos ultrassons, e proporcionando interdisciplinaridade entre as matérias de física, biologia e ciências, o que contribui, de maneira importante, no processo de aprendizagem dos alunos (CARDOSO-SILVA; OLIVEIRA, 2013).

Um equívoco foi encontrado na obra de EF13, na qual morcegos-vampiros são considerados aqueles que se utilizam da ecolocalização, subentendendo-se, erroneamente, que todos os morcegos possuem o hábito alimentar hematófago.

EM06 (p. 181) apresentam forte influência cultural ao questionar "Por que a forte vibração de longas taquaras à noite, em um local onde voam morcegos, pode dificultar a ecolocalização desses animais?”. Essa prática popular é inapropriadamente usada para desorientar os mamíferos voadores, e a questão levantada em nada contribui para a formação do aluno, devendo, os professores, estar preparados para lidar com a discussão levantada pois, tal menção no texto didático pode despertar a curiosidade dos leitores à prática e estimular o contato direto com esses animais.

Figura 6. Esquemas do funcionamento dos sonares dos morcegos, conhecidos como ecolocalização

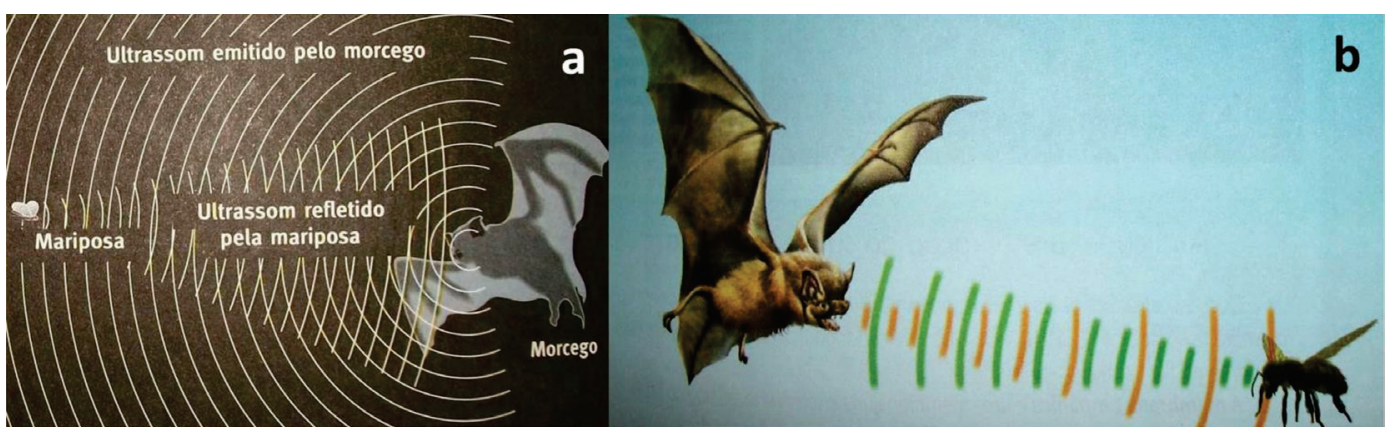

Fontes: (a) EF05 e (b) EF13. 


\section{Hibernação}

EM09 (p. 328) foram os únicos a abordar a hibernação utilizada por morcegos e o fizeram comparando-a com "uma espécie de sono profundo", a fim de facilitar o entendimento do tema. No entanto, os autores pouco explicam que a estratégia é adotada por morcegos de climas temperados para superar a escassez de alimentos e as exigências energéticas elevadas devido às temperaturas reduzidas (AUGUSTO, 2008), quando ocorre a redução da temperatura corporal e da taxa metabólica do animal para economia de temperatura e água (STAWSKI; WILLIS; GEISER, 2014). O livro tampouco esclarece que esta tática de sobrevivência não é utilizada por morcegos que vivem em climas tropicais, como é o caso do Brasil.

\section{Enfoques das informações}

As abordagens evolutivas (35\%) foram consideradas satisfatórias devido à apresentação de informações aliadas que, na maioria das vezes, ilustram e comparam facilitando o aprendizado dos leitores sobre: a comparação de estruturas corporais, as modificações a partir de um ancestral em comum com outros grupos animais, a modificação das mãos em asas como adaptação para o voo dos morcegos e as alterações das flores quiropterofílicas para este tipo de polinização.

Grande parte dos textos com enfoque zoológico (3\%) e biológico (24\%) foi superficial ao tratar das características do grupo Chiroptera e apresentar aspectos genéricos, sem explicações aprofundadas ou diferenciadas. A prevalência epidemiológica (4\%) também foi considerada carente de explanações sobre o processo de transmissão do vírus da raiva. Além disso, tais explanações não trazem informações seguras a respeito da doença, sendo que deveriam ser incluídos elementos profiláticos na forma de advertências como, por exemplo, "Não se aproxime de animais silvestres desconhecidos" ou "não toque em animais silvestres mortos ou caídos no chão".

$\mathrm{Na}$ ecologia (34\%), foram estabelecidas relações entre os morcegos e o ambiente de forma ampla, tanto na sua ocorrência em ambientes favoráveis, na utilização do sonar para a captura de alimentos ou para desviar de obstáculos, como também nas relações de predação, dispersão de sementes ou polinização. O estudo de Scavroni, Paleari e Uieda (2008), realizado na cidade de Botucatu (São Paulo), mostrou que quase 50\% das crianças da $3^{a}$ série do ensino fundamental de escolas públicas acreditavam que quirópteros não tinham importância ecológica e 93\% delas pensavam que existiam apenas morcegos de hábito alimentar hematófago. O trabalho de Silva et al. (2009) mostrou que quase 10\% dos alunos de Japurá (Paraná) desconheciam qualquer importância ecológica desse grupo de vertebrados. Silva, Manfrinato e Anacleto (2013) também mostraram que mais de 70\% dos alunos de uma escola estadual do Mato Grosso acreditavam que morcegos não traziam qualquer benefício para a natureza.

Apesar de a abordagem ecológica estar presente nos livros didáticos deste trabalho, os estudos apontados anteriormente sobre a percepção e conhecimentos dos alunos sobre os morcegos evidenciam a importância dos docentes trabalharem, com afinco e dedicação, os conhecimentos proporcionados pelos morcegos ao ecossistema. Também devem ser estimuladas as leituras de livros didáticos que enfatizem essas relações ecológicas e seus benefícios, como as de:

1) EM09 e EF02, que apresentam discursos voltados aos benefícios ecológicos, modificando o olhar leigo da população sobre os morcegos; 
2) EM09 (p. 258), que esclarecem a utilização do termo "vampiro" e mencionam o controle populacional realizado por morcegos, as crenças e as superstições dos animais que são perseguidos e exterminados na cidade do Recife, PE: "Os morcegos..., podem até lembrar vampiros, mas, de sugadores de sangue eles têm muito pouco...", além de enfatizar seus papéis ecológicos: “ [...] Os morcegos que comem insetos ou se alimentam do néctar de flores prestam um serviço especialmente precioso ao equilíbrio ecológico da capital de Pernambuco, explica o biólogo."

3) EF02 também discorreu sobre os benefícios do controle populacional e da dispersão e polinização para a regeneração de florestas. Além disso, estabeleceu uma comparação entre morcegos e ser humano: ambos são mamíferos, amamentam suas crias, possuem pelos pelo corpo e regulagem da própria temperatura.

\section{Conclusões}

A maior parte dos materiais educacionais que abordaram o tema foi considerada suficiente em relação à inclusão de títulos atrativos, linguagem acessível e utilização de recursos visuais. Ainda que necessitem de ajustes, o emprego das imagens é indispensável, pois, ao estabelecer o contato inicial, essas provocam o leitor, estimulando a busca do conhecimento. Embora poucos erros conceituais ou informações distorcidas estivessem presentes nos livros, a qualidade informativa relacionada aos quirópteros foi considerada insatisfatória devido à tímida exploração dos conceitos e os discursos, superficiais pela pobreza do conteúdo científico.

Os trechos com influência histórico-cultural sobre os mistérios envolvendo os morcegos precisam ser considerados e esclarecidos no ensino de ciências e biologia. A ênfase nas informações sobre os diversos papéis ecológicos dos quirópteros e a utilização de textos que estimulam o aprendizado despertam a curiosidade para a pesquisa e para a conservação das espécies, contribuindo para o desenvolvimento das habilidades científicas dos estudantes. Ao mesmo tempo, informações médico-sanitárias e profiláticas devem ser adicionadas como forma de contribuição à saúde pública brasileira.

Em colaboração com o ensino formal, as escolas devem expandir o acesso ao conhecimento e realizar atividades abertas à comunidade leiga, como, palestras, seminários, visitas ao ar livre em centros de preservação ambiental ou oficinas, voltados à divulgação científica, de modo a auxiliar na consolidação de atividades em prol da conservação dos morcegos. 


\section{Referências}

ALBAS, A. et al. Perfil antigênico do vírus da raiva isolado de diferentes espécies de morcegos não hematófagos da região de Presidente Prudente, Estado de São Paulo. Revista da Sociedade Brasileira de Medicina Tropical, Uberaba, v. 42, n. 1, p. 15-17, 2009. Disponível em: <http://dx.doi.org/10.1590/S0037-86822009000100004>. Acesso em: 24 maio 2016.

AMARAL, I. A.; MEGID NETO, J. Qualidade do livro didático de ciências: o que define e quem define? Ciência \& Ensino, Campinas, n. 2, p. 17-18, 1997. Disponível em: <https:// www.fe.unicamp.br/gepce/publicacoesgepCE.html>. Acesso em: 24 maio 2016.

ASSIS, S. S.; PIMENTA, D. N.; SCHALL, V. T. A dengue nos livros didáticos de ciências e biologia indicados pelo Programa Nacional do Livro Didático. Ciência \& Educação, Bauru, v. 19, n. 3, p. 633-656, 2013. Disponível em: < http://dx.doi.org/10.1590/S1516$73132013000300009>$. Acesso em: 24 maio 2016.

AUGUSTO, A. M. P. S. Actividade de Myotis myotis (Chiroptera) durante o inverno: influência da abundância alimentar. 2008. 42 f. Dissertação (Mestrado em Biologia da Conservação) - Faculdade de Ciências, Universidade de Lisboa, Lisboa, 2008. Disponível em: <http://hdl.handle.net/10451/1176>. Acesso em: 24 maio 2016.

BATISTA, H. B. C. R.; FRANCO, A. C.; ROEHE, P. M. Raiva: uma breve revisão. Acta Scientiae Veterinariae, Porto Alegre, v. 35, n. 2, p. 125-144, 2007. Disponível em: <http:// www.ufrgs.br/actavet/35-2/artigo718.pdf>. Acesso em: 24 maio 2016.

BRASIL. Ministério da Educação. PNLD: apresentação. Disponível em: < http://portal.mec. gov.br $/$ index.php?option $=$ com_content\&view $=$ article $\& i d=12391 \&$ Itemid $=668>$. Acesso em: 18 jun. 2013.

BRASIL. Ministério da Saúde. Morcegos em áreas urbanas e rurais: manual de manejo e controle. 2. ed. Brasília: Fundação Nacional de Saúde, 1998.

CAJAIBA, R. L. Morcegos (Mammalia, Chiroptera) em cavernas no município de Uruará, Pará, norte do Brasil. Biota Amazônia, Macapá, v. 4, n. 1, p. 81-86, 2014. Disponível em: $<$ https://periodicos.unifap.br/index.php/biota/article/view/888/v4n1p81-86.pdf>. Acesso em: 24 maio 2016.

CARDOSO-SILVA, C. B.; OLIVEIRA, A. C. Como os livros didáticos de biologia abordam as diferentes formas de estimar a biodiversidade? Ciência \& Educação, Bauru, v. 19, n. 1, p. 169-180, 2013. Disponível em: <http://dx.doi.org/10.1590/S1516-73132013000100012>. Acesso em: 24 maio 2016.

COELHO, F. C. R. et al. Metaheurística inspirada na ecolocalização de morcegos: aperfeiçoamento e estudo de casos. In: SIMPÓSIO BRASILEIRO DE PESQUISA OPERACIONAL, 2012, Rio de Janeiro. Anais... Rio de Janeiro: CLAIO: SBPO, 2012. p. 2588-2599. Disponível em: <http://www.din.uem.br/sbpo/sbpo2012/pdf/arq0372.pdf>. Acesso em: 24 maio 2016. 
COSTA, C. C. A.; OLIVEIRA, F. L. Polinização: serviços ecossistêmicos e o seu uso na agricultura. Revista Verde de Agroecologia e Desenvolvimento Sustentável, Mossoró, v. 8, n. 3, p. 1-10, 2013. Disponível em: <http://www.gvaa.com.br/revista/index.php/ RVADS/article/view/2598/2010>. Acesso em: 24 maio 2016.

FERREIRA, A. M.; SOARES, C. A. A. A. Aracnídeos peçonhentos: análise das informações nos livros didáticos de ciências. Ciência \& Educação, Bauru, v. 14, n. 2, p. 307-314, 2008. Disponível em: <http://dx.doi.org/10.1590/S1516-73132008000200009>. Acesso em: 24 maio 2016.

MACHADO, N. J. Sobre livros didáticos: quatro pontos. Em Aberto, Brasília, v. 16, n. 69, p. 30-38, jan./mar, 1996.

MEGID NETO, J.; FRACALANZA, H. O livro didático de ciências: problemas e soluções. Ciência \& Educação, Bauru, v. 9, n. 2, p. 147-157, 2003. Disponível em: <http://dx.doi. org/10.1590/S1516-73132003000200001>. Acesso em: 24 maio 2016.

MOHR, A. A saúde na escola: análise de livros didáticos de 1a a 4a séries. 1994. 100 f. Dissertação (Mestrado em Educação) - Instituto de Estudos Avançados em Educação, Fundação Getúlio Vargas, Rio de Janeiro, 1994. Disponível em: < http://bibliotecadigital.fgv. $\mathrm{br} / \mathrm{dspace} / \mathrm{bitstream} /$ handle/10438/9092/000061139.pdf? sequence=1>. Acesso em: 24 maio 2016.

MOLINA, O. Quem engana quem: professor x livro didático. Campinas: Papirus, 1987.

OLIVEIRA, J. C. T.; SILVA, L. A. M. Imaginário infantil e sua percepção sobre morcegos. In: CONGRESSO DE INICIAÇÃO CIENTÍFICA, 17., 2009, Recife. Caderno de resumos... Recife: Propesq, 2009.

PACHECO, S. M. et al. Morcegos urbanos: status do conhecimento e plano de ação para a conservação no Brasil. Chiroptera Neotropical, Brasília, v. 16, n. 1, p. 629-647, 2010.

PAGLIA, A. P. et al. Lista anotada dos mamíferos do Brasil / Annotated checklist of Brazilian Mammals. 2. ed. Arlington: Conservation International, 2012. (Occasional papers in conservation biology, 6). Disponível em: <http://www.conservation.org/global/brasil/ publicacoes/Documents/annotated_checklist_of_brazilian_mammals_2nd_edition.pdf $>$. Acesso em: 24 maio 2016.

PAIVA, V. M. F. Educação ambiental: impacto na percepção e mudança de atitudes em relação aos morcegos. 2010. 54 f. Dissertação (Mestrado em Ecologia e Gestão Ambiental) - Faculdade de Ciências, Universidade de Lisboa, Lisboa, 2010. Disponível em: < http://hdl. handle.net/10451/3467>. Acesso em: 24 maio 2016.

RAMOS, L. H. M. Epizootia de raiva na região leste do município de Campinas, SP de 2000 a 2002. 2009. 92 f. Dissertação (Mestrado em Saúde Coletiva) - Faculdade de Ciências Médicas, Universidade Estadual de Campinas, 2009. Disponível em: < http://www. bibliotecadigital.unicamp.br/document/?code=000442795>. Acesso em: 24 maio 2016.

REIS, N. R. et al. Sobre os morcegos brasileiros. In: (Org.). Morcegos do Brasil. Londrina: EDUEL, 2007. p. 17-26. 
RUPPENTHAL, R.; SCHETINGER, M. R. C. O sistema respiratório nos livros didáticos de ciências das séries iniciais: uma análise do conteúdo, das imagens e atividades. Ciência \& Educação, Bauru, v. 19, n. 3, p. 617-632, 2013. Disponível em: < http:/ /dx.doi. org/10.1590/S1516-73132013000300008>. Acesso em: 24 maio 2016.

\section{SALGADO, S. S. Invertebrados associados a guano de morcegos em cavernas do}

Distrito Federal. 2011. 90 f. Dissertação (Mestrado em Ecologia) - Universidade de Brasília, Brasilia, 2011. Disponível em: < http://repositorio.unb.br/handle/10482/12874>. Acesso em: 24 maio 2016.

SANDRIN, M. F. N.; PUORTO, G.; NARDI, R. Serpentes e acidentes ofídicos: um estudo sobre erros conceituais em livros didáticos. Investigações em Ensino de Ciências, Porto Alegre, v. 10, n. 3, p. 281-298, 2005.

SÃO PAULO (Estado). Secretaria de Estado da Educação. Currículo do Estado de São Paulo: ciências da natureza e suas tecnologias. São Paulo, 2011.

SCAVRONI, J.; PALEARI, L. M.; UIEDA, W. Morcegos: realidade e fantasia na concepção de crianças de área rural e urbana de Botucatu, SP. Simbio-logias, Botucatu, v. 1, n. 2, p. 1-18, 2008. Disponível em: < http://www.ibb.unesp.br/Home/Departamentos/Educacao/ Simbio-Logias/artigo_edu_morcegos_realidade_fantais_concepcao_criancas_a.pdf $>$. Acesso em: 24 maio 2016.

SILVA, L. R. et al. Informações preliminares sobre a percepção dos alunos de $1^{a}$ a $3^{a}$ séries do ensino médio no município de Japurá, Paraná, acerca da importância dos morcegos. In: ENCONTRO MARINGAENSE DE BIOLOGIA, 11., 2009, Maringá. Resumo de trabalhos científicos... Disponível em: <http://old.dbi.uem.br/Ensino_Biologia2009.pdf>. Acesso em: 24 maio 2016.

SILVA, S. G.; MANFRINATO, M. H. V.; ANACLETO, T. C. S. Morcegos: percepção dos alunos do ensino fundamental $3^{\circ}$ e $4^{\circ}$ ciclos e práticas de educação ambiental. Ciência \& Educação, Bauru, v. 19, n. 4, p. 859-877, 2013. Disponível em: < http://dx.doi. org/10.1590/S1516-73132013000400006>. Acesso em: 24 maio 2016.

STAWSKI, C.; WILLIS, C. K. R.; GEISER, F. The importance of temporal heterothermy in bats. Journal of Zoology, London, v. 292, n. 2, p. 86-100, 2014.

SUCCI, C. M.; WICKBOLD, D.; SUCCI, R. C. M. A vacinação no conteúdo de livros escolares. Revista da Associação Médica Brasileira, São Paulo, v. 52, n. 2, p. 75-79, 2005. Disponível em: <http://dx.doi.org/10.1590/S0104-42302005000200013>. Acesso em: 24 maio 2016.

TELES, A. J. et al. Histoplasmose em cães e gatos no Brasil. Science and Animal Health, Pelotas, v. 2, n. 1, p. 50-66, 2014. Disponível em: <https://periodicos.ufpel.edu.br/ojs2/ index.php/veterinaria/article/view/2978/3025>. Acesso em: 24 maio 2016.

UIEDA, W. História natural dos morcegos hematófagos no Brasil. In: PACHECO, S. M.; MARQUES, R. V.; ESBÉRARD, C. E. L. (Org.). Morcegos no Brasil: biologia, sistemática, ecologia e conservação. Porto Alegre: Armazém Digital, 2007. p. 179-198. 
VERÇOZA, F. C. et al. Polinização e dispersão de sementes de Dyssochoma viridiflora (Sims) Miers (Solanaceae) por morcegos no Parquie Nacional da Tijuca, um remanescente de Floresta Atlântica no sudeste do Brasil. Natureza On Line, Santa Teresa, v. 10, n. 1, p. 7-11, 2012. Disponível em: < http://www.naturezaonline.com.br/natureza/conteudo/pdf/03_ Ver\%C3\%A7ozaFCetal_007011.pdf>. Acesso em: 24 maio 2016.

YAMAMOTO, L. F.; KINOSHITA, L. S.; MARTINS, F. R. Síndromes de polinização e de dispersão em fragmentos da Floresta Estacional Semidecídua Montana, SP, Brasil. Acta Botânica Brasilica, Belo Horizonte, v. 21, n. 3, p. 553-573, 2007. Disponível em: < http:// dx.doi.org/10.1590/S0102-33062007000300005>. Acesso em: 24 maio 2016.

Artigo recebido em 22/05/2015. Aceito em 21/12/2015.

Endereço para contato: Universidade Estadual de Maringá, Departamento de Ciências, Avenida Colombo, 5790, Jardim Universitário, CEP 87020-900, Maringá, PR, Brasil. 